\title{
Arte e Educação Especial: narrativas e criações artísticas
}

\author{
Art and Special Education: narrative and artistic creations
}

Arte y Educación Especial: narrativas y creaciones artísticas

\section{* Flávia Gurniski Beltrami}

Mestre pela Universidade Estadual de Maringá, Maringá, Paraná, Brasil.

flaviagurniski@hotmail.com

\section{** Nerli Nonato Ribeiro Mori \\ Professora doutora na Universidade Estadual de Maringá, Maringá, Paraná, Brasil. nnrmori@uem.br}

Recebido em 27 de abril de 2019

Aprovado em 17 de julho de 2019

Publicado em 12 de setembro de 2019

\section{RESUMO}

Este trabalho apresenta parte da pesquisa de Mestrado em Educação que discute a arte como forma de conhecimento e sensibilidade no processo de criação artística na Educação Especial em um contexto de inclusão. A pesquisa justifica-se pela necessidade de estudos que contribuam com a percepção de mundo, com a interação de uns com os outros de forma que o processo de criação artística seja concebido como fonte de humanização, considerando determinações sociais, históricas e culturais. Nossa investigação parte da seguinte indagação: como ocorre o desenvolvimento de narrativas e criações artísticas por meio da arte? Para respondermos a essa questão, tivemos, como objetivo geral, investigar o desenvolvimento de narrativas e criações artísticas por meio da arte mediante intervenção educacional que integra um grupo de alunos com necessidades especiais, da sala de recursos multifuncionais de uma escola municipal, no Município de Maringá-PR. A pesquisa está fundamentada na teoria Histórico Cultural, objetivando: evidenciar a arte como fonte de humanização; discutir de forma breve o ensino de Arte no Brasil e Educação Especial; destacar a arte popular e a importância das narrativas; promover encontros mobilizando o processo de criação artística e análise, exemplificando uma produção artística. A metodologia da pesquisa é qualitativa, envolvendo estudos bibliográficos e pesquisa participante. Em nossas considerações finais, com os resultados alcançados no trabalho realizado, defendemos a importância do ensino de Arte para o desenvolvimento cognitivo e sensível do aluno, pois este viabiliza a construção do pensamento e um espaço de discussão.

Palavras-chave: Educação especial; Arte; Processo criativo. 


\section{ABSTRACT}

This article presents a part of a research of a Master course in Education that discusses art as a way to knowledge and sensitivity in the process of artistic creation in Special Education in an inclusion process. This research justifies by the need of studies which contribute to the perception of the world, with the interaction with each other in a way that the process of artistic creation is conceived as a source of humanization, considering social, historical and cultural determinations. Our investigation starts with the following questioning: how does occur the narrative and artistic creation development through art? In order to answer this question, we had, as a main goal, investigate the narrative development and artistic creation through art with educational intervention which integrates a group of students with special needs, in a multifunctional resource classroom in a municipal school, in the city of Maringá - PR. This research is based on the Historical Critical Theory, aiming: to emphasize art as a source of humanization; discuss in a brief way the teaching of Art in Brazil and Special education; highlight the popular art and the importance of narratives; promote gatherings mobilizing the process of artistic creation and analyses, exemplifying one artistic production. The methodology for this research is qualitative, involving bibliographical studies and participant research. In our final considerations, with the reached results with this work, we defend the importance of teaching Art for the student's cognitive and sensitive development, because this favors the construction of thought and a space of discussion.

Keywords: Special education; Art; Creative process.

\section{RESUMEN}

El trabajo presenta parte de la investigación de maestría que trata del arte como conocimiento y sensibilidad en el proceso de creación artística en la Educación Especial en contexto de inclusión. Se justifica por la necesidad de contribuir con los estudios sobre la visón de mundo, con la interación entre las personas para que el proceso de creación artística sea concebido como humanizador, en vista de las determinaciones sociales, históricas y culturales. El trabajo propone la siguiente pregunta: ¿cómo ocurre el desarrollo de las narrativas y de las creaciones artísticas por el arte? Para contestarla, se ha propuesto el objetivo general de investigar el desarrollo de narrativas y de creaciones artísticas por el arte con el uso de intervención educativa de integración de un grupo de alumnos en situación de discapaciad, en clase de recursos multifuncionales, de una escuela del condado de Maringá-PR. La investigación se basa en la teoría Histórico Cultural y presenta los siguientes objetivos específicos: poner en evidencia el arte en Brasil como fuente de humanización; discutir de manera breve la enseñanza del arte en Brasil y la Educación Especial; apuntar la importancia del arte popular y de las narrativas; hacer encuentros que movilicen el proceso de creación artística. La metodología tiene abordaje cualitativo y carácter bibliográfica así como es del tipo participante. Los resultados permiten la defensa de la enseñanza del arte para el desarrollo cognitivo y sensible del alumno, una vez que el arte viabiliza la construcción del pensamiento y de uno espacio de discusión.

Palabras-clave: Educación especial; Arte; Proceso creativo. 


\section{Introdução}

Este trabalho apresenta parte da pesquisa de Mestrado, desenvolvida no Programa de Pós-Graduação em Educação da Universidade Estadual de Maringá (UEM) que teve como objeto de estudo discutir a arte como forma de conhecimento e sensibilidade no processo de criação artística na Educação Especial em um contexto de inclusão. Neste estudo, ao destacarmos a arte como área de conhecimento disciplinar, utilizamos o termo com inicial maiúscula, conforme consta nas Diretrizes Curriculares do Estado do Paraná (DCEs) para o ensino de Arte (PARANÁ, 2008).

Salientamos a importância deste estudo, no campo acadêmico-científico, pela necessidade constante de um número maior de pesquisas que estruturem o conhecimento em arte como fonte de humanização, considerando determinações sociais, históricas e culturais como constituinte da imagem artística enquanto linguagem. No campo profissional e social observamos que tal aprofundamento pode fazer a diferença nas ações pedagógicas.

A problematização dessa pesquisa consiste em buscar respostas para: como ocorre o desenvolvimento de narrativas e criações artísticas por meio da arte? Para responder a essa questão, tivemos como objetivo geral investigar o desenvolvimento de narrativas e criações artísticas por meio da arte, com ênfase na Educação Especial. Propomos uma pesquisa teórica e prática a partir da perspectiva histórica cultural e da arte, objetivando: evidenciar a arte como fonte de humanização; discutir de forma breve o ensino de Arte no Brasil e Educação Especial; destacar a arte popular e a importância das narrativas; promover encontros mobilizando o processo de criação artística com análise de uma produção artística.

Buscamos evidenciar a arte como fonte de humanização, visto que, desde os primórdios da humanidade, as pessoas modificaram a natureza produzindo instrumentos, conceberam sua história e o processo de trabalho transformando seu cotidiano. Concomitantemente, discutimos de forma sistematizada o ensino de Arte no Brasil voltado para a Educação Especial, como forma de demonstrar os avanços e desafios nessa área de conhecimento. Destacamos a arte popular e a importância das narrativas, uma vez que ela é formada pela camada social constituída por trabalhadores e artistas que representam seus objetivos, interesses e suas ideias ao se expressarem nos objetos artísticos que produzem. 
Para o enquadramento teórico e metodológico da pesquisa, a metodologia utilizada é de caráter qualitativo, o referencial de estudos e as análises estão fundamentados na perspectiva da Teoria Histórico Cultural e da Arte. O procedimento utilizado é de cunho bibliográfico levando em consideração os indicativos de Gil (2007), visto que o autor conceitua os trabalhos científicos de acordo com a finalidade geral, e com base no recorte e no assunto a ser abordado. A pesquisa classifica-se em concordância com seu objetivo geral e admite as definições da pesquisa exploratória que tem como meta principal o aperfeiçoamento de ideias proporcionando "[...] maior familiaridade com o problema, com vistas a torná-lo mais explícito" (GIL, 2002, p. 41).

Realizada no segundo semestre de 2017, a pesquisa participante foi elaborada, como recurso metodológico, por meio de uma intervenção educacional integrando um grupo de alunos com necessidades educacionais especiais que frequentam uma sala de recursos multifuncionais de uma escola da Rede Pública Municipal de Maringá, Paraná. A pesquisa que envolve participantes, segundo Minayo (2009), estabelece uma relação com a realidade, mediando e promovendo a superação das dificuldades de um determinado grupo social. Segundo a autora, a ciência se constitui em um instrumento de construção do conhecimento expandindo suas raízes no campo das experiências do cotidiano.

Para a metodologia e os procedimentos utilizados na organização dos encontros o conteúdo trabalhado focou a arte popular, na qual expomos sobre a vida e a obra do artista contemporâneo Hélio Leites (1951), apresentando algumas de suas representações artísticas. Tais propostas desdobraram-se em contextualização referente ao conteúdo proposto, apreciação de imagens e o fazer artístico, conforme referências das Diretrizes Curriculares do Estado do Paraná (DCEs) para o ensino de Arte (PARANÁ, 2008). Especificamos a metodologia e os procedimentos utilizados na organização dos encontros abordando os momentos do ensino de Arte: teorizar, sentir e perceber o fazer artístico.

Registramos, de forma sistematizada, a experiência estética e artística vivenciada, expondo algumas falas e expressões de um participante da pesquisa. $O$ método de análise focaliza o processo criativo que envolve a criação do objeto artístico concomitante à produção de narrativas orais desenvolvidas pelo aluno. Assim, no processo de análise, demonstramos a passagem do concreto para o abstrato e vice e versa. Analisamos se 0 aluno apresentou iniciativa e autonomia na construção do objeto artístico e produção de narrativas orais; o que foi produzido pelo aluno; sua forma de interagir com os colegas 
durante os encontros; simbolização mediada; elaboração objetiva e elaboração subjetiva; forma e conteúdo.

Com os resultados alcançados, e em resposta ao problema da pesquisa, evidenciamos que o desenvolvimento de narrativas e criações artísticas por meio da arte ocorre mediante os conteúdos significativos vivenciados no processo de criação, pela experiência estética e artística. O trabalho realizado indica a relevância do ensino de Arte para o desenvolvimento cognitivo e sensível do aluno, com necessidades especiais, pois propicia a construção do pensamento e a comunicação entre os pares.

\section{Considerações em Arte e Educação Especial}

Desde o princípio, o ser humano transformou a natureza em objetos e ferramentas, construiu sua história, a sociedade e também o processo do trabalho; transformando a sua própria existência. Por esse motivo, tornou-se capaz de simbolizar, criar um mundo humano e humanizar-se. Ao se apropriar da natureza, a pessoa se apropria de si mesmo e, com isso, a arte é tida como um trabalho humano de importância, pois ela expressa sua essência na criação de objetos artísticos. Nesse sentido, a arte como fonte de humanização precisa ter como ponto de partida a sua realidade, sob uma perspectiva histórica, social e cultural, permitindo um olhar sobre a realidade humana e social, apontando possibilidades de novos caminhos para esta realidade.

Desde os primórdios da humanidade, os objetos artísticos ganham um significado que extrapola a função utilitária, vinculando-se ao sensível e ao mundo simbólico. A arte envolve formas distintas do ser, articulando o pensar e o agir segundo o conhecimento acumulado pela humanidade, como também, a criação da capacidade de comunicar-se, por meio da linguagem, do pensamento e da ação. Fischer (1983) salienta que a arte é influenciada pelo seu tempo e representa a humanidade em entendimento com ideias, necessidades e esperanças de uma situação histórica particular.

De acordo com o processo histórico de constituição do ensino de Arte no Brasil com a Lei de Diretrizes e Bases da Educação Nacional, Lei n. 9.394/1996 (BRASIL, 1996) e a publicação dos Parâmetros Curriculares Nacionais (PCNs) de Arte (BRASIL, 1998), 0 ensino de Arte foi reconfigurado no país. Como apontam as DCEs (PARANÁ, 2008), os PCNs publicados no período de 1997 e 1999 em Arte, foram encaminhados pelo Ministério de Educação (MEC), firmando-se como referência nacional para o ensino de Arte. Segundo Ferraz e Fusari (2009), esses documentos vieram para normatizar a situação ocorrendo, 
uma consolidação da área e o seu reconhecimento em relação à formação e ao desenvolvimento humano. Nesse sentido, a Arte é um componente de "[...] área do conhecimento obrigatório em toda a educação básica e compete aos órgãos públicos como conselhos, secretarias de educação e escolas tratarem de sua melhor inserção no currículo escolar" (FERRAZ; FUSARI, 2009, p. 58).

No Estado do Paraná, a partir de 2003, formularam-se as DCEs da disciplina de Arte, promulgada em 2008, após um movimento intenso de discussões coletivas que envolveram professores da área, os Núcleos Regionais de Educação (NRE) e Instituições de Ensino Superior (IES). As DCEs (PARANÁ, 2008) são um documento de referência no ensino de Arte, com o propósito de fortalecer a educação pública do estado. Assim, um dos aspectos relevantes deste documento, consiste na ação conjunta dos professores, que efetuaram estudos e leituras críticas no decorrer da programação das semanas pedagógicas, coordenadas pelos Núcleos Regionais de Educação (NRE). Os estudos eram sistematizados e enviados à Secretaria de Estado da Educação (SEED), envolvendo as várias áreas de conhecimento, entre elas, a disciplina de Arte.

A atual Lei de Diretrizes e Bases da Educação Nacional (BRASIL, 2017, p. 40), Lei n 9.394/1996, no artigo 59, inciso I, divulga que os sistemas de ensino devem assegurar aos alunos currículo, métodos, recursos e organização específicos para atender às suas necessidades. Ao enfatizarmos que o aluno, com necessidades educacionais especiais, necessita de um ensino significativo para que avance; consideramos que a "[...] atividade artística deve ser parte integrante do currículo do ensino especial, oferecida a todos. [...]. Isso porque a arte faz parte do nosso dia-a-dia e tem função importante na nossa cultura" (REILY, 2001, p. 266).

Para discutirmos o ensino de Arte na Educação Especial, levamos em consideração que o aluno, na educação inclusiva, não pode ser incluso somente na presença física, mas também na cognitiva, apresentando concepções de mundo de forma significativa. Durante o processo de criação artística, isso é observado de forma concreta. Para Vigotsky (2007), todos podem aprender, pois somos seres sociais e históricos, uma vez que "[...] as funções mentais superiores são socialmente formadas e culturalmente transmitidas" (VIGOTSKY, 2007, p. 57). Diante do exposto, podemos explicitar o que fora postulado pela Teoria Histórico Cultural a qual enfatiza que, aprendemos com a troca entre os pares e não sozinhos. Nesse sentido, defendemos que os conteúdos de Arte precisam ter como ponto 
http://dx.doi.org/10.5902/1984686X37784

de partida a realidade dos alunos com necessidades educacionais especiais, sob uma perspectiva histórica e cultural.

O atendimento educacional especializado tem como função elaborar e organizar recursos pedagógicos, metodologias educacionais e acessibilidade que eliminem as barreiras para a plena participação dos alunos considerando suas necessidades específicas, "[...] para que estes possam apropriar-se dos conhecimentos oferecidos pela escola" (SHIMAZAKI; MORI, 2012, p. 31). A possibilidade de ensino para esses alunos é aquela que se preocupa com o desenvolvimento de formas assimiladas com as áreas do conhecimento humano contextualizado. Pessoas com necessidades especiais serão eficientes desde que sejam oferecidas a elas oportunidades sociais que respeitem e atendam às suas necessidades. Em vista disso, os sistemas de ensino devem estruturarse com serviços de apoio para esse atendimento em classes, escolas ou serviços especializados, quando não for possível a integração desses alunos com deficiências específicas em classes comuns de ensino regular.

Shimazaki e Mori (2012, p. 35), citam que por meio da Declaração de Salamanca de 1994, que teve seu início na Conferência Mundial sobre Educação para Todos em 1990, foi desenvolvido "[...] um documento de princípio político e de prática para as necessidades educativas especiais". Assim, essa Declaração proclama que as escolas regulares com orientação inclusiva constituem os meios mais eficazes de combater atitudes discriminatórias e que alunos com necessidades especiais devem ter acesso à escola regular.

O documento Declaração de Salamanca, e linha de ação sobre necessidades educativas especiais ${ }^{1}$ aborda o conceito de inclusão e

[...] parte do princípio de que todas as diferenças humanas são normais e de que a aprendizagem deve, portanto, ajustar-se às necessidades de cada criança, em vez de cada criança se adaptar aos supostos princípios quanto ao ritmo e à natureza do processo educativo. Uma pedagogia centralizada na criança é positiva para todos os alunos e, consequentemente, para toda a sociedade (BRASIL, 1997, p.18).

Nesse contexto, é indispensável que todas as crianças possam aprender juntamente com seus pares, em um contexto de inclusão, mesmo com suas diferenças e dificuldades, pois a integração e a participação são fundamentais à "[...] dignidade humana e do gozo e

\footnotetext{
${ }^{1}$ A Declaração de Salamanca foi publicada em 1994 e reeditada em 1997, com impressão no Brasil, sendo traduzida por Edilson Alkmin da Cunha com direitos autorais cedidos à CORDE pela UNESCO e Ministério da Educação e Ciência, Espanha.
} 
exercício dos direitos humanos. No campo da educação, essa situação se reflete no desenvolvimento de estratégias que possibilitem uma autêntica igualdade de oportunidades" (BRASIL, 1997, p. 23). Para que isso ocorra, "[...] as escolas inclusivas devem reconhecer as diferenças e necessidades dos alunos [...] e assegurar um ensino de qualidade por meio de um adequado programa de estudos" (SHIMAZAKI; MORI, 2012, p. 35).

O sistema educacional brasileiro precisa propiciar aos alunos com necessidades especiais os direitos básicos para que eles possam se desenvolver em um contexto social e cultural. A Arte no currículo escolar, para esses alunos geralmente é trabalhada de forma restrita e isso é demonstrado nas palavras de Reily (2001) fundamentada na sua experiência como arte educadora, para alunos com deficiência intelectual, quando escreve:

[...] encontramos muitas vezes desenhos que se apoiam em esquemas relativamente cristalizados, num repertório bastante restrito: também é frequente vermos desenhos e pinturas que revelam interesse em aspectos decorativos, sequenciados, tanto de ordem temática (sequência de flores, listas coloridas no telhado) quanto ordem abstrata (faixas de cor, pontilhados, separações de áreas etc.) (REILY, 2001, p. 141).

É indispensável que, na disciplina de Arte, o professor procure formas diferenciadas de ensino para que o aluno absorva o conhecimento como fonte de humanização. O aluno, ao entrar em contato com a Arte, por meio do ensino, pode estimular e ampliar o seu conhecimento e a sua percepção, e isso pode ser aplicado em qualquer área. Nesse sentido, essa proximidade com a arte será importante para o desenvolvimento das funções psicológicas, pois, no processo artístico, poderá ser estimulada a memória, a atenção e a percepção.

Reily (2010) explica que com as políticas públicas de garantia do direito e acesso ao aluno com necessidades especiais no ensino regular, houve um considerável número de matrículas de inclusão, principalmente, no ensino fundamental nas escolas municipais. Dessa maneira,

[...] a partir do movimento de inclusão, começam a ocorrer possibilidades de convivência na heterogeneidade dentro da escola que abrem múltiplas oportunidades de aprendizado, não somente para os alunos, como também para os professores, que, via de regra, em se tratando dos especialistas de áreas curriculares específicas, não teve em sua formação pedagógica disciplinas que contemplassem conteúdos de educação especial. Em contato com alunos com deficiência, os professores de arte vão percebendo a necessidade de prover recursos ou atenção especial para o atendimento das especificidades de cada aluno (REILY, 2010, p. 86). 
No ensino de Arte, é essencial o professor procurar buscar conteúdos específicos, mas ele sente dificuldade para desenvolver um trabalho relevante com os alunos da Educação Especial. Conforme a autora, alguns estudos de pesquisadores em relação ao tema arte e inclusão mostram-se pertinentes, porém muitas práticas artísticas colocam o ensino de Arte como um recurso terapêutico. É fundamental desenvolver um trabalho em arte no contexto escolar, sem direcioná-la a um mero auxílio terapêutico, uma vez que o bom ensino "[...] é somente aquele que se adianta ao desenvolvimento" (VIGOTSKY, 2007, p. 102).

É necessário trabalhar o cognitivo e o sensível no processo de criação artística, buscando trazer um conhecimento significativo para que o aluno, com necessidades especiais, possa se desenvolver e ser incluso na sociedade, uma vez que "[...] é exatamente a atividade criadora que faz do homem um ser que se volta para o futuro, erigindo-o e modificando no seu presente" (VIGOTSKI, 2009, p.14). A arte faz parte do movimento da história da humanidade; nesse sentido, é necessário projetar as experiências individuais e coletivas em práticas concretas e significativas no contexto escolar, para alunos com necessidade especiais, não excluindo alunos sem deficiência.

\section{Arte popular e a importância das narrativas}

A arte popular propicia representar, em seu processo artístico, a materialidade e a cultura de um povo, com ações e conhecimentos necessários à formação histórica e social. Como aponta Canclini (1980), ela é produzida pela camada social constituída por trabalhadores e artistas que representam os seus objetivos, interesses e ideias ao se expressarem nos objetos artísticos que produzem. Segundo Canclini (1980, p. 50), "[...] a arte popular é uma arte de libertação" e para ser entendida como forma de autonomia para as pessoas, é necessário "[...] apelar não só a sensibilidade e a imaginação, mas também a capacidade de conhecimento e ação" (CANCLINI, 1980, p. 50).

Como salienta Fischer (1983), a arte produzida pelo povo, surge de uma necessidade coletiva para expressar e representar as ideias da sociedade, assim é construída historicamente pelo conjunto de tradições de uma sociedade e vai sendo modificada de acordo com as necessidades coletivas, por meio de ações e conhecimentos. Desse modo, essa arte futuramente será criada "[...] com o que vão produzindo os povos, mas também com os documentos, objetos e imagens herdados" (CANCLINI, 1980, p. 207). Para que os indícios do passado possam contribuir com a percepção do presente, eles devem ser 
revisados e entendidos, mediante uma perspectiva inovadora marcada por diferentes relações sociais que as criaram.

O artista contemporâneo passa a utilizar materiais inusitados em seu processo de criação, alguns artistas empregaram no passado ao criarem um novo conceito de arte. Canclini (1980, p. 106) explica que, apenas com a "[...] chegada do século XX, inicia-se o processo de autonomia do campo cultural, o isolamento dos artistas e a superestima de seu trabalho". Segundo o autor, foi com a chegada das artes de vanguardas, que os artistas começaram a produzir seus trabalhos com objetos incomuns, impulsionando, assim, a busca de autonomia na arte.

Argan (1992) argumenta que o artista Marcel Duchamp integrou um dos movimentos de vanguarda, chamado de Dadaísmo. O movimento ignorou as experiências formais e os métodos anteriores ao renunciar as técnicas tradicionais artísticas e, com essa atitude, os dadaístas demonstraram interesse em utilizar objetos da produção industrial.

Alguns trabalhos de artistas contemporâneos têm relação com a obra de Duchamp, visto que transformam objetos comuns, atribuindo a eles uma ressignificação diferente da sua funcionalidade, pois concede aos materiais inusitados, usados em seus trabalhos, um novo conceito. Assim, "[...] a obra de Duchamp contém em embrião os desenvolvimentos que os artistas que virão depois dele farão crescer, num sentido ou noutro: a arte conceitual" (CAUQUELIN, 2010, p. 69). Antes a função primordial atribuída à arte era retratar a realidade histórica de uma determinada época, mas a arte popular concomitante à arte contemporânea veio para romper com esse padrão de representação.

Cauquelin (2010) concebe o estado da arte contemporânea como um mundo de várias possibilidades, posto que a arte sempre se encontrará em constante transformação e pode ser produzida como um modo de atuação na sociedade em vários contextos. A autora destaca que o artista Duchamp rompeu com a prática estética da pintura e esse rompimento teria relação com uma transferência de poder. O artista trouxe para seu trabalho uma arte conceitual ao utilizar objetos comuns já prontos e disponíveis no cotidiano. Rompe com o que vem a ser entendido como arte, uma vez que o sentido da arte para ele está no seu conceito, ou seja, no que o artista pretende expressar e representar ao produzir a sua obra, e não somente onde seu trabalho é exposto para poder ser reconhecido, com valor artístico.

A abordagem da arte popular no processo criativo concomitante a produção de narrativas é significativa, pois tem o objetivo de proporcionar um caminho à imaginação 
criadora e a interação entre os alunos. É na narrativa que segundo Benjamim (2012, p. 217), "[...] o narrador retira o que ele conta da experiência: de sua própria experiência ou da relatada por outros. E incorpora, por sua vez, as coisas narradas à experiência dos seus ouvintes". Assim, por meio das narrativas orais podem ser preservadas as tradições populares ou até mesmo ser ressignificadas em outro contexto e em conjunto com a produção artística abrirá o domínio a novos conhecimentos. Nesse sentido, o professor poderá conduzir o aluno a um novo olhar para a formação de novos conceitos, pois, "[...] o material sensorial e a palavra são partes indispensáveis à formação de conceitos" (VYGOTSKY, 2008, p. 66).

No processo de criação de narrativas orais concomitantes à produção artística, o aluno além de expressar a sua subjetividade tem a possibilidade de manifestar o conhecimento adquirido com seus pares, mediante a experiência estética, uma vez que para Benjamim (2012, p. 213) o conceito de narrativa é descrito como "[...] a faculdade de intercambiar experiências", pois a narrativa é uma forma artesanal de comunicação entre as pessoas.

\section{Processo de criação artística e análise de dados}

Ao apresentarmos a pesquisa, levamos em conta uma das ações referentes à Educação Especial, a inclusão dos alunos na sociedade em que vivem. Nosso objetivo inicial foi proporcionar um estímulo à percepção visual para após potencializar a imaginação criadora dos alunos para a criação dos trabalhos e construções das narrativas, pois para Vigotsky (2007, p. 103), "[...] o aprendizado adequadamente organizado resulta em desenvolvimento mental e põe em movimento vários processos de desenvolvimento".

Com sete participantes na pesquisa, as intervenções educacionais foram organizadas em dez encontros semanais, nos dois períodos: matutino e vespertino, com $2 \mathrm{~h}$ de intervenção em cada período, nas segundas-feiras. No decorrer do registro da intervenção os participantes tiveram seus nomes alterados como forma de preservar sua identidade. Utilizamos as letras iniciais do nome com a idade de cada um, bem como, pontuamos as respectivas escolaridades, conforme segue: GPS (11 anos), $2^{\circ}$ ano; GABS (10 anos), $4^{\circ}$ ano; DCSS (12 anos) $4^{\circ}$ ano; PLCS (13 anos), $4^{\circ}$ ano; ALSS, (13 anos) $5^{\circ}$ ano; JTM, (09 anos) $3^{\circ}$ ano; e KSL (16 anos), 3ำ ano. Para tanto, devido ao recorte da pesquisa, demonstraremos somente um exemplo da produção artística concomitante à análise. Assim, utilizaremos as letras iniciais do nome com a idade, conforme segue: KSL (16 anos), um aluno com deficiência Intelectual e Física/Neuromotor. 
Para a realização da intervenção educacional com os alunos, utilizamos, como procedimentos metodológicos, a criação artística e a produção de narrativas orais, por meio da prática artística e do objeto criado. O método foi pautado nos três momentos da organização pedagógica: teorizar, sentir e perceber e o trabalho artístico, segundo as DCEs de Arte (PARANÁ, 2008). Como os critérios de análises são fundamentados com base na perspectiva da Teoria Histórico Cultural, também analisamos os dados colhidos mediante os três momentos das Diretrizes.

No trabalho artístico com os alunos, utilizamos como referência o artista paranaense Hélio Leites (1951) com o seu Teatro de Boné, (entre 1999 e 2010), com referência em (PIRES, 2008, p. 89). Os trabalhos do artista apresentam uma relação com as obras do artista Marcel Duchamp, visto que ambos utilizam, em suas criações artísticas, materiais inusitados atribuindo a eles um novo sentido, sendo assim "[...] a arte reflete a infinita capacidade humana para a associação, para a circulação de experiências e ideias" (FISCHER, 1983, p. 13). Esse modo de aproximação de ideias "[...] torna-se possível somente graças à experiência alheia ou experiência social" (VIGOTSKI, 2009, p. 24).

De acordo com Vigotski (2009) é com essa experiência, que observamos a importância da apresentação do trabalho de Hélio Leites e suas narrativas para o contexto escolar, uma vez que é

[...] somente num estágio bem superior de acúmulo de experiência, somente num estágio superior de domínio da fala, somente num estágio superior de desenvolvimento do mundo pessoal e interno da criança, torna-se acessível à criação literária (VIGOTSKI, 2009, p. 62-63).

Além das experiências adquiridas pelo convívio social é necessário trazer para as escolas novas possibilidades de se fazer arte com artistas que sejam referências para que possamos impulsionar no aluno o seu potencial criador, visto que "[...] a educação correta consiste em despertar na criança aquilo que existe nela, ajudar para que isso se desenvolva e orientar esse desenvolvimento para algum lado" (VIGOTSKI, 2009, p. 72).

Pires (2008) ressalta que, o artista Hélio Leites possui uma didática com processo de transformação em suas oficinas, uma vez que "[...] ensina não só o trabalho com a embalagem, mas incentiva a busca da luz individual, da história de cada um, do processo artístico" (PIRES, 2008, p. 33). A autora destaca que seus trabalhos artísticos são produzidos com diversas temáticas e narrativas voltadas às questões do cotidiano, a personagens da literatura, a poesias entre outros. Além disso, sua arte é acompanhada quase sempre de um texto escrito no próprio objeto artístico. 
Ao utilizamos como objeto de estudo os trabalhos do artista Hélio Leites, promovemos estudos de criação junto a vários objetos que foram disponibilizados aos alunos, durante os encontros, para que pudessem manipular ressignificar e transformar esses materiais em trabalhos artísticos significativos. Ao desenvolvermos um trabalho de produção de narrativas orais junto ao processo criativo dos alunos, utilizamos como referência o autor Rodari (1982), com base em seu argumento quando sugere que "[...] se quisermos ensinar a pensar, devemos primeiro ensinar a inventar" (RODARI, 1982, p.148, grifos do autor).

Para incentivar o aluno na criação de narrativas Rodari (1982), tem um método que pode contribuir para estimular a imaginação criadora do aluno. Conforme o autor, "[...] a técnica das 'hipóteses fantásticas' é muito simples. Sua forma precisa é a da pergunta: $\mathrm{O}$ que aconteceria se... Para se formular a pergunta escolhe-se ao acaso um sujeito e um predicado. A sua união fornecerá a hipótese sobre a qual se deve trabalhar" (RODARI, 1982, p. 27). Ao fazermos uso desse método, utilizaremos a fantasia para estabelecer relações com a vida.

A manipulação de determinados objetos selecionados pelo professor durante a atividade artística pode contribuir de forma significativa para o desenvolvimento cognitivo do aluno, visto que "[...] a imaginação trabalha apenas com materiais colhidos da realidade, é preciso que a criança [...] possa crescer em um ambiente rico de impulsos e estímulos, em todas as direções" (RODARI, 1982, p. 139). Proporcionar condições ao aluno, com necessidades especiais, para que ele possa ter um contato com a arte, por meio da metodologia proposta, pode estimular a comunicação, a linguagem e a imaginação ao produzir narrativas, a partir da criação do trabalho artístico e, com isso, cultivar a criatividade para outras áreas de conhecimento, uma vez que "[...] a imaginação da criança, estimulada a inventar palavras, aplicará seus instrumentos sobre todos os traços da experiência, que provocarão sua intervenção criativa" (RODARI, 1982, p. 139).

No processo de análise, determinamos relações por meio dos dados obtidos durante a intervenção educacional e a fundamentação teórica. $O$ desenvolvimento do processo criativo foi concretizado pela ação e reflexão durante o fazer de cada participante. A intervenção educacional, por meio da arte, proporcionou aos alunos demonstrarem suas potencialidades, tais como a imaginação, sensibilidade, percepção e observação, que podem vir a contribuir para o entendimento de conteúdos de outras áreas do conhecimento. Sobre isso, Vigotski salienta que "[...] qualquer vivência intensa, a vivência estética cria uma 
atitude muito sensível para os atos posteriores e, evidentemente, nunca passa sem deixar vestígios para o nosso comportamento" (VIGOTSKY, 2010, p. 342).

Para as análises dos dados, utilizamos as gravações de áudio do processo de criação artística dos participantes. Ao expor os resultados da pesquisa, selecionamos alguns momentos de falas no decorrer do processo de criação. No decurso dos encontros, observamos o poder da arte ao proporcionar a interação entre os alunos. Nosso intuito foi formar um olhar diferenciado durante os encontros, estimulando a comunicação e a linguagem e também a imaginação e a criação dos participantes no processo de criação, pela mediação de conteúdos em artes e experiências vivenciadas pelos alunos.

As Diretrizes Curriculares do Estado do Paraná (DCEs) para o ensino de Arte (PARANÁ, 2008) propõem encaminhamentos metodológicos, em que o conhecimento, as práticas e a fruição artística aconteçam de forma integrada na ação pedagógica. Com este foco, elas apresentam uma metodologia de ensino de Arte composta por três momentos: teorizar, sentir e perceber e trabalho artístico. Propomos um trabalho de criação para a intervenção educacional, tendo como referencial as obras do artista popular Hélio Leites, a partir dos momentos propostos pelas DCEs para o ensino de Arte.

Como forma de teorizar, falamos sobre a vida do artista contemporâneo Hélio Leites demonstrando um vídeo do artista e também representações de imagens de seus trabalhos artísticos, por meio de livros. Após uma breve exposição sobre a vida e trabalhos do artista, perguntamos aos alunos o que conseguiram perceber em relação ao que acabaram de ouvir e visualizar, mas, em um primeiro momento, houve apenas um silêncio.

Em seguida, continuamos as atividades com a inserção de leitura de imagens de alguns trabalhos do artista, pautada na crença de que, para um processo de conhecimento em arte, as ilustrações e textos visuais podem estimular a percepção, imaginação e a aprendizagem que consequentemente poderá contribuir no processo criativo dos alunos. Sobre isso, Schlichta (2009) argumenta que,

[...] a leitura de imagens é uma das principais práticas no âmbito do ensino de artes visuais, pois enriquece a compreensão que os alunos têm de si mesmos e do mundo e, concomitantemente, a sua experiência [...] trata-se de uma maneira especificamente humana não só de assimilar, mas, sobretudo, de produzir representações fundamentadas na história humana e social (SCHLICHTA, 2009, p. 60).

A leitura de imagens faz parte do sentir e perceber um dos momentos dos encaminhamentos metodológicos, em que oferecem a oportunidade para a apreciação, 
fruição, leitura e acesso das obras de arte, dos objetos da natureza e da cultura, possibilitando o estímulo dos sentidos, como aponta as DCEs (PARANÁ, 2008). Quanto maior o conhecimento em arte, mais profundo será o processo de fruição e de percepção.

No decorrer das leituras de imagens, observamos que todos os alunos, em um primeiro momento, somente especificavam as cores que faziam parte da composição do trabalho do artista e após a explicação referente aos trabalhos, os alunos começaram a ter um novo olhar e não ficaram apenas tentando adivinhar o que havia nas imagens e as cores que o artista utilizou, posto que "[...] o mundo não é visto simplesmente em cor e forma, mas também como um mundo com sentido e significado" (VIGOTSKY, 2007, p. 24).

No transcorrer da descrição dos encontros, observamos que os alunos começaram a perceber o que o artista quis representar e expressar ao criar o seu trabalho artístico. Sobre isso, Vigotski explica que a percepção humana "[...] é parte de um sistema dinâmico de comportamento; por isso, a relação entre as transformações dos processos perceptivos e as transformações em outras atividades intelectuais é de fundamental importância" (VIGOTSKY, 2007, p. 24).

Nas primeiras mediações, notamos uma modificação na forma de entendimento dos alunos em relação ao trabalho do artista. Além disso, houve uma interação entre eles ao argumentarem sobre o que o artista pretendia representar em cada trabalho e os objetos que ele utilizou para a criação artística. Para Vigotsky (2010) e demais autores, é fundamental a mediação do professor com a linguagem, objetos e imagens, assim podemos considerar esses elementos como uma forma significativa para o desenvolvimento da cognição e sensibilidade do aluno com necessidades especiais, posto que "[...] a arte transfigura a realidade não só nas construções da fantasia, mas também na elaboração real dos objetos e situações" (VIGOTSKY, 2010, p. 352).

As primeiras intervenções foram significativas para conhecermos a fase de desenvolvimento dos alunos em relação ao conhecimento em arte. Conforme Vigotski (2009) é importante cultivar a imaginação criadora e, portanto, as imagens surgidas para a criação devem ser embasadas na experiência, pois é no contexto social que podemos criar e produzir o novo. Para o autor, não se cria sem referências com a realidade, "[...] o desenvolvimento da criança não é um processo espontâneo, linear e natural: é um trabalho de construção do homem sobre o homem" (VIGOTSKI, 2009, p.10). 
Seguindo nossas análises, passamos para o processo criativo com os trabalhos artísticos e as produções das narrativas. Conforme as DCEs (PARANÁ, 2008), o trabalho artístico consiste em uma prática artística criativa, um exercício de criação e imaginação, em que o aluno coloca em prática o conteúdo. Para o desenvolvimento das narrativas foi importante utilizarmos o método proposto Rodari (1982), considerando que, desde o início do processo de criação com a manipulação e separação dos objetos, e também com a escolha das cores para compor o cenário, os alunos já começaram a pensar em suas produções. A metodologia das hipóteses fantásticas foi fundamental para que eles demonstrassem o potencial criador, tendo em vista que, "[...] criar é difícil. A necessidade de criar nem sempre coincide com as possibilidades de criação e disso surge um sentimento de sofrimento de que a ideia não foi para a palavra" (VIGOTSKI, 2009, p. 55).

No processo de criação dos alunos, algumas associações levaram a reflexões interessantes. De acordo com Vygotsky (2008), para a formação de novos conceitos, a criança passa por três fases que se dividem em diversos estágios, em uma dessas fases está o pensamento por complexos. O estágio de desenvolvimento por complexos é demarcado por relações concretas que acontecem, por meio da prática da criança com o objeto. O pensamento por complexos se subdividem em cinco estágios que ocorrem um depois do outro, sem uma identificação precisa de quando um começa e o outro termina. Destacamos dentre esses estágios o complexo associativo que "[...] pode basear-se em qualquer relação percebida pela criança entre o objeto" (VYGOTSKY, 2008, p. 77). Evidenciamos esse tipo de complexo ao percebermos algumas manifestações associadas no decorrer dos encontros, quando os participantes estabeleceram ligações entre os objetos.

Como exemplo, consideramos alguns conceitos manifestados e outros adquiridos no decorrer da intervenção educacional do aluno KSL (16 anos), que independentemente das dificuldades na sua oralidade e sem poder trabalhar com as mãos, mas somente com a boca, conseguiu desenvolver a narrativa e realizar o trabalho artístico mediante o auxílio de todos. Ao escolher objetos para compor a sua narrativa, mesmo não conseguindo tocá-los, devido à sua deficiência, foi comunicando-se e ordenando-os, conforme imaginava a sua história.

Em relação à pintura dos objetos e do boné, KSL (16 anos) conseguiu pintá-los com um adaptador bucal, pois a sua deficiência o impede de ter autocontrole de braços e mãos. 
Apesar disso, teve iniciativa e autonomia ao escolher as cores azul, cinza, branca e preta para compor seu cenário. Misturamos as cores preta e branca até conseguirmos a tonalidade da cor cinza, conforme imaginou. Sendo assim, usou a cor azul para representar o céu, a cor branca ao dar pinceladas para fazer a representação das nuvens e a cor preta para representar uma via, a qual simboliza o trajeto de viagem da sua personagem.

Ainda que não pudesse manusear o pincel com as mãos, KSL (16 anos) foi bastante detalhista em relação à estética do seu trabalho. Quando não conseguia pintar do modo que imaginava, ficava um pouco incomodado, demonstrando preocupação em fazer o seu trabalho da melhor forma possível. Ficou apreensivo quando não conseguiu fazer o movimento preciso com o pincel ao pincelar com a cor cinza a aba do boné, deixando-o tocar delicadamente a parte superior, o qual já estava pintado com a cor azul. Então, ao explicarmos que na linha do horizonte podemos observar às vezes relevos, que são formas de montanha, ficou contente por seu trabalho poder ter uma ressignificação para além do que havia imaginado. Dessa forma, por meio das mediações, ele percebeu que alguns acabamentos que não conseguiu concluir poderiam ser representados de um modo diferente e compreendeu que na arte pode haver vários acasos no decorrer do processo de criação.

As hipóteses fantásticas de Rodari (1982) favoreceram a comunicação do aluno com o grupo e proporcionaram o desenvolvimento de diversas possibilidades de ações entre as suas personagens, principalmente, os diálogos no decorrer da sua história entre animais e a pessoa. Isso só foi possível quando o aluno entendeu que, em algumas narrativas, assim como as fábulas, os animais podem se comunicar, por meio da linguagem humana. Para Vigotski (2009, p. 32), "[...] essa construção fantasiosa parte diretamente da realidade e nela influi. Só que essa realidade não é externa, e sim interna - o mundo das ideias, dos sentimentos próprios do homem".

Em seu trabalho, intitulado "Davi o viajante", o aluno expressou, em seu processo criativo, algo que é distante da sua realidade, a sensação de liberdade, ou seja, o desejo de conseguir se locomover sozinho para vários lugares. Ao materializar seus sentimentos, por meio de sensações e pensamentos, KLS (16 anos) tornou evidente que "[...] as imagens da fantasia servem de expressão interna de nossos sentimentos. [...] o sentimento seleciona elementos isolados da realidade" (VIGOTSKI, 2009, p. 26). Segue a imagem do trabalho artístico produzido pelo aluno, como mostra a Figura 1: 
Figura 1 - Trabalho artístico de KSL (16 anos)

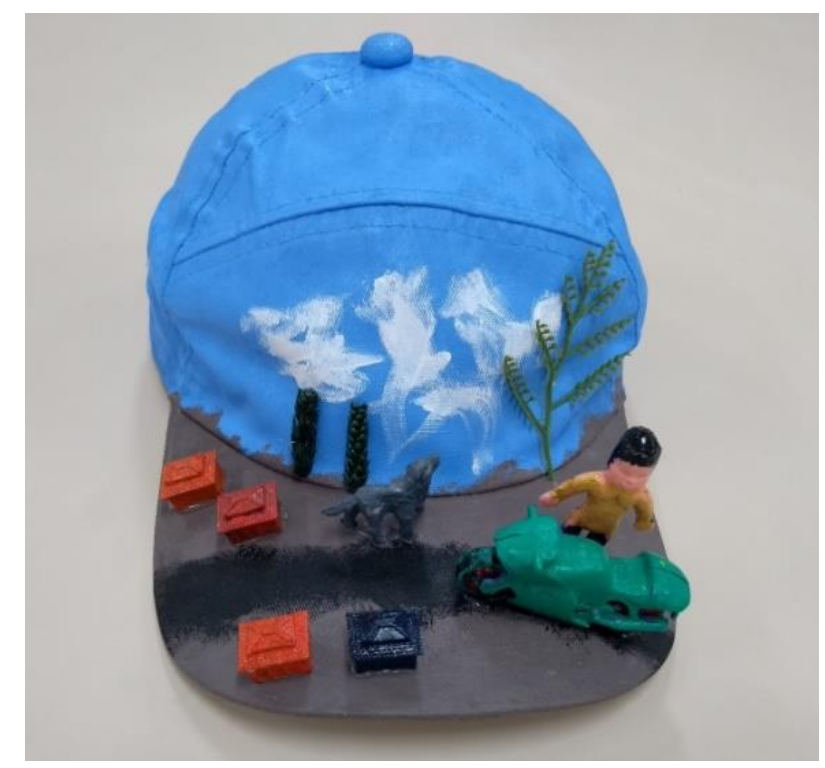

Fonte: Flávia Gurniski Beltrami, 2017.

Para a exposição dos trabalhos, o aluno propôs o título "Histórias de Boné", o qual, segundo ele, está relacionado às várias histórias que foram narradas durante todo o processo artístico. Sendo assim, o título "Histórias de Boné" foi pertinente, pois, ao visualizarmos os objetos dispostos em cada boné, as pessoas podem imaginar diversas narrativas em um único trabalho produzido, sendo que "[...] não só interpretamos de modo diferente as obras de arte como as vivenciamos de maneira também diferente" (VYGOTSKY, 1999, p. 48). Perante o exposto, ficou nítida a capacidade de superação mediante as limitações que se apresentavam no processo criativo do aluno.

No processo de criação, KSL (16 anos) manifestou vivências do cotidiano e ocorreram algumas situações que o levou a refletir no desenvolvimento da narrativa e produção artística. A problematização dessas situações no processo artístico possivelmente provocou estímulos para o processo de formação de conceitos; "[...] para que o processo se inicie, deve surgir um problema que só possa ser resolvido pela formação de novos conceitos" (VYGOTSKY, 2008, p. 68). O sujeito, ao criar, busca captar e configurar a realidade que o cerca ao tentar compreender a sua vida e o mundo.

Sendo assim, não devemos esquecer que

[...] a lei principal da criação infantil consiste em ver seu valor não no resultado, não no produto da criação, mas no processo. O importante não é o que as crianças criam, o importante é que criam, compõem, exercitam-se na imaginação criativa e na encarnação dessa imaginação (VIGOTSKI, 2009, p. 100). 
Nas reflexões provocadas no processo de criação, durante as intervenções educacionais, alguns conceitos foram modificados, porque os alunos perceberam que os trabalhos desenvolvidos em arte podem estar repletos de significações e não restritos somente a um fazer sem sentido. Com as produções de vários trabalhos, por meio de cores e materiais inusitados concomitantes à produção de narrativas, o trabalho desenvolvido em arte junto aos participantes da pesquisa pode ter oportunizado a aprendizagem de conceitos da linguagem artística, e também algumas modificações nas funções psicológicas superiores.

\section{Considerações finais}

A necessidade de estudos que contribuam com a percepção de mundo de modo que o processo de criação artística seja concebido como fonte de humanização, com a comunicação entre os alunos, foi o motivo pelo qual desenvolvemos este trabalho. Para que o ensino de Arte contribua com o processo de humanização, ele deve estar relacionado à realidade das pessoas, considerando determinações sociais, históricas e culturais; permitindo possibilidades de transformação dessa realidade. Consideramos que o ensino de Arte faz surgir a ação histórica e social desenvolvida pela humanidade, em uma práxis criadora, pois a arte "[...] é um produto resultante do movimento dialético ação/pensamento/ação que se concretiza em objetos artísticos" (PARANÁ, 2008, p. 52).

Tornamos evidente que, por intermédio da arte, é possível um interpretar da realidade, um novo olhar, um novo fazer de experiências teóricas e práticas no decorrer do processo de ensino e aprendizagem. A humanização pela arte acontece com a apropriação do conhecimento historicamente sistematizado pela humanidade, mas não um conhecimento que gera uma ação distante da vida das pessoas possível apenas a alguns favorecidos. A arte é criação carregada de conhecimento e sensibilidade, uma relação com o mundo que propicia uma ação mediadora do ser humano para com o outro.

Ensinar Arte é mais do que ensinar cores e formas, é buscar identificação com a humanidade e proporcionar condições aos alunos, com necessidades especiais, de apreenderem o conhecimento constituído ao longo da história humana. Sendo assim, estudar Arte é importante para que eles conheçam a sua realidade e possam refletir e, consequentemente, agir conscientes sobre o mundo em que se encontram. Tendo em vista que se pode criar e construir algo novo, um novo olhar, nas relações sociais e na cultura, historicamente elaborada, sendo que "[...] não se cria do nada. A particularidade da criação 
no âmbito individual implica, sempre, um modo de apropriação e participação na cultura da história" (VIGOTSKI, 2009, p. 10).

Observamos que, durante a realização dos encontros, os alunos começaram a entender o que o artista representou e expressou em suas criações artísticas. Ao produzirem os trabalhos artísticos, ficaram nítidas a capacidade de entendimento e a superação do grupo, mediante as limitações que se apresentavam inicialmente. Ao trazermos um artista popular contemporâneo como referencial para a nossa intervenção educacional, destacamos que o ensino de Arte não pode ficar estagnado somente às obras de grandes clássicos. Sem dúvida, as criações de artistas contemporâneos também são inspiradores para elaboração de um trabalho significativo no contexto escolar.

A abordagem da arte popular no processo criativo foi relevante e objetivou estímulos à imaginação criadora dos participantes. Construída historicamente pelo conjunto de tradições de uma sociedade, ela vai se transformando de acordo com as necessidades coletivas, representando no processo artístico a materialidade e a cultura das pessoas, com ações e conhecimentos necessários à formação histórica, social e cultural.

No decorrer do processo de criação, os alunos tiveram a oportunidade de refletirem sobre o fazer artístico, trazendo aproximações da realidade vigente em suas produções. A arte como representação do pensamento humano foi expressa tanto no objeto materializado quanto nas narrativas orais, tornando-se um caminho para a interação do grupo. Cada participante teve no seu ritmo de desenvolvimento artístico algumas dificuldades, mas que foram superadas de forma satisfatória.

Para responder a nossa problemática: como ocorre o desenvolvimento de narrativas e criações artísticas por meio da arte? Tivemos, como objetivo geral, a investigação do desenvolvimento de narrativas e de criações artísticas por meio da arte, com ênfase na Educação Especial. Demonstramos, com os resultados alcançados durante os encontros, que o desenvolvimento dessas habilidades em Arte ocorre mediante os conteúdos significativos vivenciados no processo de criação, pela experiência estética e artística.

Concluímos que é importante planejar um trabalho educacional mediante práticas significativas, elencadas em conhecimento e ação para que o aluno, com necessidades especiais, possa construir um novo olhar, mediante o cognitivo e o sensível no processo de criação artística. Reiteramos a importância do conhecimento em Arte, pois possibilita um espaço de discussão entre as pessoas e a construção do pensamento. 


\section{Referências}

ARGAN, Giulio Carlo. Arte Moderna. 2. ed. Tradução: Denise Bottmann e Federico Carotti. São Paulo: Companhia das Letras, 1992.

BENJAMIM, Walter. Magia e Técnica, Arte e Política: ensaios sobre literatura e história da cultura. 8. ed. Tradução: Sérgio Paulo Rouanet. São Paulo: Brasiliense, 2012. (Obras Escolhidas v.1).

BRASIL. Conferência Mundial sobre Necessidades Educativas Especiais: Acesso e Qualidade (1994: Salamanca). Declaração de Salamanca, e linha de ação sobre necessidades educativas especiais. 2. ed. Tradução: Edilson Alkmim da Cunha. Brasília, DF: CORDE, 1997. 54p.

BRASIL. Lei no 9.394, de 20 de dezembro de 1996. Estabelece as Diretrizes e Bases da Educação Nacional. 1996.

BRASIL. LDB: Lei de Diretrizes e Bases da Educação Nacional. Brasília, DF: Senado Federal, Coordenação de Edições Técnicas, 2017. 58p.

BRASIL. Secretaria de Educação Fundamental. Parâmetros curriculares nacionais: arte. Secretaria de Educação Fundamental. Brasília, DF: MEC /SEF, 1998. 130p.

CANCLINI, Néstor García. A Socialização da Arte: teoria e prática na América Latina. 1. ed. São Paulo: Cultrix, 1980.

CAUQUELIN, Anne. Arte contemporânea. Tradução: Claudete Soares. Men Martins, Portugal: Europa-América, 2010. (Coleção Saber; 273).

FERRAZ, Maria Heloísa Corrêa de Toledo; FUSARI, Maria Felisminda de Rezende e. Metodologia do ensino de arte: fundamentos e proposições. 2. ed. São Paulo: Cortez, 2009.

FISCHER, Ernest. A Necessidade da Arte. 9. ed. Tradução: Leandro Konder. Rio de Janeiro: Zahar Editores, 1983.

GIL, Antônio Carlos. Como elaborar projetos de pesquisa. 4. ed. São Paulo: Atlas, 2007.

MINAYO, Maria Cecília de Souza. O Desafio da Pesquisa Social. In: DESLANDES, Suely Ferreira; GOMES, Romeu; MINAYO, Maria Cecília de Souza (Org.). Pesquisa Social: teoria, método e criatividade. 28. ed. Petrópolis, Rio de Janeiro: Vozes, 2009, p. 21.

PARANÁ. Secretaria de Estado da Educação. Departamento de Educação Básica. Diretrizes Curriculares de Arte para a Educação Básica. Curitiba: SEED/DEB, 2008. 100p.

PIRES, Rita de Cássia Baduy. Pequenas grandezas: miniaturas de Hélio Leites. 1. ed. Curitiba: Artes \& Textos, 2008. 
REILY, Lúcia. Armazém de imagens: ensaio sobre a produção artística da pessoa com deficiência. 1. ed. Campinas: Papirus: 2001.

REILY, Lucia. O Ensino de Artes Visuais na Escola no Contexto da Inclusão. Cadernos Cedes, Campinas, vol. 30, n. 80, p. 84-102, jan./abr., 2010. Disponível em: http://www.scielo.br/pdf/ccedes/v30n80/v30n80a07.pdf. Acesso em: 9 mar. 2018.

RODARI, Gianni. Gramática da fantasia. Tradução Antônio Negrini. 8. ed. São Paulo: Summus, 1982.

SCHLICHTA, Consuelo. Arte e educação: há um lugar para a arte no ensino médio. 1. ed. Curitiba: Aymará, 2009.

SHIMAZAKI, Elza Midori; MORI, Nerli Nonato Ribeiro. Fundamentos da Educação Especial. In: MORI, Nerli Nonato Ribeiro; JACOBSEN, Cristina Cerezuela. (Org.). Atendimento Educacional Especializado no contexto da Educação Básica. 1. ed. Maringá: EDUEM, 2012, p. 31-39.

VÁZQUEZ, Adolfo Sánchez. As ideias estéticas de Marx. 2. ed. Rio de Janeiro: Paz e terra, 1978.

VIGOTSKY, Lev Semyonovich. Psicologia pedagógica. Tradução Paulo Bezerra. 3. ed. São Paulo: Martins Fontes, 2010

VIGOTSKY, Lev Semyonovich. A formação social da mente: o desenvolvimento dos processos psicológicos superiores. 7. ed. Tradução José Cipolla Neto, Luís Silveira Menna Barreto, Solange Castro Afeche. São Paulo: Martins Fontes, 2007.

VIGOTSKI, Lev Semyonovich. Imaginação e criação na infância: ensaio psicológico. 1. ed. Apresentação e comentários Ana Luiza Smolka. Tradução de Zoia Prestes. São Paulo: Ática, 2009. (Coleção Ensaios comentados).

VYGOTSKY, Lev Semyonovich. Pensamento e linguagem. 4. ed. Tradução Jefferson Luiz Camargo. São Paulo: Martins Fontes, 2008.

VYGOTSKY, Lev Semyonovich. Psicologia da Arte. 1. ed. Tradução Paulo Bezerra. São Paulo: Martins Fontes, 1999.

\section{Correspondência}

Flávia Gurniski Beltrami - Universidade Estadual de Maringá. Av. Colombo, 5790 Zona 7. CEP: 87020-900. Maringá, Paraná, Brasil.

This work is licensed under a Creative Commons Attribution-NonCommercial 4.0 International (CC BY-NC 4.0) 
